\title{
Effects of Victimization on the Belief in a Just World in Four Ex-Yugoslavian Countries
}

\author{
Rachel Fasel - Dario Spini
}

Published online: 19 March 2010

(C) Springer Science+Business Media, LLC 2010

\begin{abstract}
Levels of support for just world beliefs among young adults $(N=598)$ from four ex-Yugoslavian countries-Bosnia and Herzegovina, Croatia, the former Yugoslav Republic of Macedonia, and Slovenia-were compared, taking into account victimization experiences and the general belief in a just world. Being a victim affected an individual's belief in a just world in the two less economically favored contexts: Victims of exclusion in Macedonia and victims of war in Bosnia and Herzegovina were less likely to believe in a just world than non-victims. These victimization variables partly explained why the mean scores of these two countries were less than those of the two others. A deleterious effect of cumulative negative events on belief in a just world was identified, in parallel with a lower endorsement of the belief when the first victimization occurred more recently.
\end{abstract}

Keywords Belief in a just world · War · Economic precariousness · Victimization · Cross-cultural comparison

\section{Introduction}

Some studies on the belief in a just world take into account the point of view of the victim confronted with a situation of injustice and consider this belief to be a resource. In general, these studies are founded on the assumption that the belief in a just world remains stable throughout time and across situations (Dalbert, 2001; Otto, Boos, Dalbert, Schöps, \& Hoyer, 2006; Schneider, Meissner, Montada, \& Reichle, 1987). However, some studies show differences in just world beliefs among

R. Fasel $(\bowtie) \cdot$ D. Spini

Faculty of Social and Political Sciences, University of Lausanne, Labo PaVie, Bâtiment Vidy, 1015 Lausanne, Switzerland

e-mail: rachel.faselhunziker@unil.ch 
countries and among groups within countries that depend on shared collective experiences (Ferguson, 2000; Furnham, 1993; Hunt, 2000; Glennon, Joseph, \& Hunter, 1993). Similarly, studies regarding fundamental beliefs (Epstein, 1973; Janoff-Bulman, 1992) show these beliefs can be altered when a person endures a traumatic event. In this case, time allows individuals to rebuild their assumptive world. In the following study, we question this vision that the belief in a just world is a stable concept, focusing on the general belief in a just world. Our hypothesis posits that there can be such victimization situations in which believing that the world is basically a just place is no longer tenable. Additionally, we hypothesize that endorsement of the belief in a just world is due to both societal and individual factors. The tensions related to the historical events in ex-Yugoslavia since the 1990s, as well as the economic precariousness of some of these countries, presented a particularly torn universe in which the individuals were strongly victimized. In such contexts, we assume that the individuals' support for the belief in a just world was shattered.

\section{Development of the Belief in a Just World}

The idea of the belief in a just world was reported for the first time in the 1960s. In the Lerner and Simmons' (1966) study, subjects rejected and depreciated an innocent victim when they believed that this person would continue suffering and, that they could not alleviate the person's suffering. The explanation of their results rested on the hypothesis of a fundamental need to believe in a just world. That is, individuals need to believe that the world is organized such that, in accordance with the way they act, people get what they deserve and deserve what they get. By rejecting and depreciating the innocent victim, subjects change their cognition to maintain the belief that people get what they deserve. According to Lerner and Miller (1978), people need to believe that the world they live in is stable and orderly. In fact, the belief in a just world serves an important adaptive function for everyday life and for the pursuit of long-term goals. Therefore, "people are very reluctant to give up this belief, and they can be greatly troubled if they encounter evidence that suggests that the world is not really just or orderly after all" (p. 1030).

Lerner $(1977,1980)$ explained that the belief in a just world emerges from the personal contract a child constructs with the world. The belief that people put in a just world, as well as the norms that allow them to evaluate what they deserve, will then be molded by their future experiences and by confrontation with their social and physical environments. These beliefs are representations of the norms and rules that one learns in a society.

\section{Interest for the Victims}

In belief in a just world literature (for reviews, see Lerner \& Miller, 1978; Furnham \& Procter, 1989), few studies examine the victims themselves and the ways that they react to what happens to them (see Furnham, 2003; Hafer \& Bègue, 2005). Since 1980, the majority of experimental studies on the belief in a just world focused on the reaction of an observer toward a third person's situation, whereas 
very few studies took into account the victims' reactions. However, the theory of the belief in a just world was not only used to explain the reaction of the observers facing a victim; the study of victims' reactions would be the extreme test of the theory (Lerner, 1980). Indeed, would a person go as far as justifying the experienced unfair treatment in order to preserve the illusory belief that the world is just? According to Hafer and Bègue (2005), scholars should also study cases of strong victimization, which are impossible to reproduce in a laboratory.

This research attempts to address this issue by showing special interest for the belief in a just world by individuals who endured victimization experiences. Is a person's belief shattered when this person lives through a traumatic experience such that he/she is less likely to believe the world is just than someone who is not a victim? Does a cumulative effect exist? That is, do more numerous negative experiences diminish the belief in a just world? If this is the case, can this belief be restored? Are some types of victimization more prone to disrupt this belief, and under what conditions? Does this effect depend upon the context in which the person evolves?

\section{Stability of Belief in a Just World?}

Several studies have examined variations in the endorsement of the belief in a just world through time and among groups or contexts. Dalbert (2001) conceptualized the belief in a just world as a personal disposition that was stable throughout time and across situations. For example, Dalbert and Schneider (1995) reported a longitudinal study in which subjects were questioned twice over the course of three months. These subjects' beliefs in a just world remained stable from the first observation point to the second. Furthermore, Dalbert (2001) reviewed the literature and concluded that individuals from different cultures have few differences in their beliefs in a just world.

Although this research finds stability in the belief in a just world, more recent studies, mainly focusing on the personal belief in a just world (i.e., the events in one's own life are considered as just; for the distinction between general and personal beliefs in a just world, see Dalbert, 1999; Lipkus, Dalbert, \& Siegler, 1996), qualify these findings. Dalbert and Stoeber (2006) showed that being treated justly in the domains of school and family positively shaped adolescents' personal belief in a just world. In the workplace, teachers who were victims of student violence (Dzuka \& Dalbert, 2007) and employees who were victims of mobbing (Cubela Adoric \& Kvartuc, 2007) perceived the world as less just for themselves than non-victims. Additionally, time spent in prison (Otto \& Dalbert, 2005) or unemployed (Cubela Adoric, 2004) was negatively associated with the personal belief in a just world among young adults.

In terms of the general belief in a just world, no difference was reported between victims and non-victims (see, for example, Cubela Adoric \& Kvartuc, 2007). However, Cubela Adoric (2004) reported variations in this belief: long-term unemployed young people were shown to adhere less to the idea that the world is a just place in general than stably employed youths. Moreover, in the unemployed sub-sample, a greater number of failed job applications was associated with a 
weaker belief in a just world. Thus, long-term unemployment and the accumulation of negative experiences diminished the endorsement of the belief that the world in general is just.

In sum, there is support for the notion that the world is considered as less just for the self to an individual who experienced a victimization episode. However, few results provide evidence that a negative personal episode may shatter an individual's belief in the idea that the world is a just place in general, which is our focus.

As far as intercultural or inter-group comparisons are concerned, several differences have been highlighted. Furnham (1993) compared the level of belief in a just and in an unjust world of psychology students from 12 world regions. He found that individuals in India and South Africa had the highest scores for belief in a just world. Both of these regions are Third World countries with extremes of wealth and poverty. According to Furnham, the rich and powerful people governing Third World societies develop a strong belief in a just world in order to reduce feelings of guilt regarding the high poverty rates. Moreover, he found a negative correlation between gross domestic product (GDP) and the belief in an unjust world. He concluded that just world beliefs are not only due to personal experiences, but also to societal functionalism. Through shared experiences, individuals develop a consensual vision of reality that is transmitted throughout time and generations.

Hunt (2000) compared the endorsement of the belief in a just world of several sub-groups in California: African Americans, Latino Americans, and whites. Latino Americans exhibited the highest levels of support for just world beliefs, followed by whites, and then African Americans. The fact that whites exhibited higher scores than African Americans reinforces the notion that more advantaged individuals have a greater motivation to consider the world as just, in order to justify their structural position and the position of the less favored groups. On the other hand, this explanation does not explain why Latino Americans displayed the highest score. Glennon et al. (1993) also observed differences between several groups in a study of university students in Northern Ireland. Students belonging to the Catholic nationalists' group had weaker scores of belief in a just world than did those of the more favored group of Unionist Protestants. Their conclusion is that group members who endure injustice are less inclined to adhere to the belief in a just world. In the same country, Ferguson (2000) reported the same pattern between Protestants and Catholics (weaker beliefs among Catholics) among a sample of 16- to 18-year-olds and suggested that this difference was due to the religious discrimination suffered by the Catholics.

A second issue raised by this study concerns changes in time. Ferguson (2000) observed a reinforcement of the belief in a just world among members of the two groups before and after the cease-fire of 1994, which launched a growing wave of hope for peace in Northern Ireland. The importance of temporal and contextual variables was also emphasized in a recent cross-temporal meta-analysis by Malahy, Rubinlicht, and Kaiser (2009). This study revealed an increase in American college students' scores on a belief in a just world scale from 1973 to 2006. This stronger adherence was positively related with the increase of income disparities at the country level. These results were explained as a response that individuals provide when their beliefs are threatened. They were interpreted in line with system 
justification theory as a rationalization of the status quo (see, for example, Kay \& Jost, 2003).

These studies on different countries or various groups within countries show that individuals' beliefs, the way in which individuals attempt to understand and explain the world, are socially anchored. Beliefs can evolve and depend on the experiences that one's own group or country has undergone. Differences are explained either by a reaffirmation of the beliefs when the system is threatened, most often by favored groups or by a reduction in this belief among groups that endure injustices.

\section{Fundamental Beliefs and Victimization}

To find other works about victims, it is helpful to examine available literature on fundamental beliefs more broadly and not restrict our field of vision to the belief in a just world. Janoff-Bulman (1992) provides a conceptual framework explaining how fundamental assumptions are shattered when people face traumatic life events. According to her, people have three fundamental assumptions: (1) the world is benevolent; (2) the world is meaningful; and (3) the self is worthy. The need for justice, which Lerner theorises as the belief in a just world, explains the fundamental assumption that the world is meaningful. These three assumptions are built in childhood and may continue to change during adolescence, but they very seldom change during adulthood. However, going through a traumatic event can strongly weaken these fundamental beliefs.

A person who undergoes a traumatic event is in such a situation that his or her fundamental assumptions are no longer in accordance with the experienced reality. The trauma causes a disintegration of his/her inner world, such that fundamental assumptions are shattered and trust in the world is crushed. The victim feels weak, helpless, meaningless, like she/he is living in a malevolent world, and his or her beliefs now conflict with prior fundamental assumptions. In the course of the healing process, the victim must rebuild his/her inner world by integrating the negative experience into one's life. It takes often weeks, months or even years to restore a balance, and the beliefs will never again be completely the same as before. Janoff-Bulman reports that, generally, the assumptive world of people that were victims is more negative than that of non-victims. These results were observed among several samples (i.e., students, adults in the middle of their lives, doctors, and hospital or crisis center inpatients) and with various types of victimization (i.e., crime, life-threatening disease, serious accident, and untimely death of a loved one).

Similar results are found regarding fundamental beliefs, as defined in the personal theories of reality by Epstein (1973) — such as the benignity or the meaningfulness of the world. Fletcher (1998; summarized in Catlin \& Epstein, 1992) followed the trajectory of Vietnam veterans, before and after their enrollment. For all veterans, the fundamental beliefs lost importance when returning from Vietnam. However, the reduction was much more consequential for ex-combatants suffering from post-traumatic stress disorder (PTSD) than for those who did not suffer from PTSD and for veterans who were not on the battlefield. Most individuals' fundamental beliefs were restored within months following their return. However, the individuals suffering from PTSD had beliefs that kept declining, even 
15 years after their battlefield experience. Catlin and Epstein (1992) observed a sample of students and found that people who experienced some negative events in their lives had less favorable levels of beliefs than those who had not been victims of these events. The authors also observed an accumulation effect: The more negative events people experienced, the less positive their beliefs. Because the negative events often happened several years before the study, their effect on basic beliefs is shown to persist over time.

In a longitudinal study (conducted in 1986 and 1989), Gluhoski and Wortman (1996) found conflicting results. No differences between waves were observed on justice beliefs for individuals who, having not gone through a traumatic event in their life before the first wave, were confronted with a close relative's or friend's death between the two waves. On the other hand, people with no prior trauma who experienced a self-focused event between the two waves considered the world as more just at the second wave. However, this effect only works to a certain extent: Individuals who have gone through several traumatic events between the waves did not have an increased score of justice. The authors explain these results with the assumption that people prefer to defend their belief that the world is just, even if they have to blame themselves and be responsible for the negative event that took place.

These contributions show that fundamental beliefs can lose their power when a person is a trauma victim; nonetheless, this effect is not observed in a stable manner for all types of victimization. A negative cumulative effect can appear when a person is a victim of several negative events. The negative effect of traumas on fundamental beliefs continues over time; nevertheless, little-by-little, individuals may succeed in rebuilding their beliefs. Because the need for justice is part of our belief system, the effect of victimization on the belief in a just world, in particular, may be also harmful. However, there is no clear evidence that the belief in a just world acts as other fundamental assumptions, since, in Gluhoski and Wortman's study (1996), the concept of justice (at the core of belief in a just world) is shown to be resistant when faced with adversity since it is even strengthened in the case of victimization aimed against the self. This result suggests it is more adaptive for such a victim to blame oneself, rather than give up the idea that the world is just. However, this effect does not seem to withstand numerous victimizations.

The presented literature leads us to think that endorsement of beliefs about justice is more resistant than other fundamental beliefs toward negative events that an individual faces. Nevertheless, a decrease in the level of support for just world beliefs is sometimes observed. We hypothesize that situations in which a degradation of the belief in a just world takes place depend on victimization experienced at the individual level—in the manner of the literature on fundamental assumptions - and, at the same time, on the way society deals with these events. Since this belief is built during childhood and adolescence in accordance with the environment, and depends on the norms and rules taught in society (Lerner, 1977), the same event experienced in two different contexts will not necessarily have the same impact on the individual's belief in a just world. Moreover, the belief in a just world is also likely to vary at a societal level when a serious event concerning the whole society occurs, such as the cease-fire in Northern Ireland (Ferguson, 2000). 
Collective experiences of war or economic vulnerability could endanger the belief in a just world at a societal level. The beliefs would be restored by confrontation with the environment and therefore depend on the structural situation in which the individual evolves.

The various theoretical approaches and empirical findings lead to the following hypotheses concerning the general belief in a just world:

(1) Social anchoring of the belief in a just world: People living in an economically precarious and war-torn context are less likely to believe that the world is just than people living in a more favored context.

(2) Personal experiences of victimization weaken the belief that the world is just.

(3) A negative cumulative effect may be observed. That is, the more victimization events a person face, the lower his/her belief in a just world.

(4) People who experienced negative events a long time ago exhibit stronger support for the belief in a just world than people who recently experienced negative events.

\section{Method}

\section{Countries in the Sample}

The data are from the pilot study of the research program Transition to Adulthood and Collective Experiences Survey (TRACES; for more details, visit www.unil.ch/traces). TRACES focuses on events due to war, conflicts, or economical precariousness that occurred since 1990 within the former Yugoslavia territory, and on their impact on people who were becoming adults during that time. For the pilot study, four countries were selected: Bosnia and Herzegovina, Croatia, Former Yugoslav Republic of Macedonia, and Slovenia.

These countries stem from the collapse of the Yugoslav Federation. However, these countries' historical processes and the socioeconomic situation differ. Slovenia was the first country of the former socialist Federal Republic of Yugoslavia to gain its independence, after a 10-day war in 1991. In the spring of 2004, Slovenia became a member of the European Union. In Croatia, war began after the country declared its independence in 1991. Although Croatia was internationally acknowledged in January 1992, conflicts took place until 1995. In February 1992, the independence referendum in Bosnia and Herzegovina was followed by a progressive launching of a triangular war between the Bosnians, Croats, and Serbians, which ended in 1995 with the signing of the Dayton Agreement. As for the Republic of Macedonia, it was spared from armed conflicts on its territory in the 1990s and acquired independence peacefully in 1991. However, in 2001, the country was hit by a relatively short and geographically limited conflict (for more historical information about ex-Yugoslavian conflicts in the 1990s, see Garde, 2000; Wilmer, 2002).

Table 1 provides a brief summary of the conflicts and the socioeconomic situation of the four countries. In Bosnia and Herzegovina and Croatia, the armed 
Table 1 Comparative situation of the four countries on socioeconomic and armed conflicts indicators

\begin{tabular}{|c|c|c|c|c|}
\hline & $\mathrm{BiH}$ & FYROM & Croatia & Slovenia \\
\hline Socioeconomic indicators & - & - & + & + \\
\hline $\mathrm{GDP}^{\mathrm{a}}$ & Low increase & Low increase & Increase & Increase \\
\hline $\mathrm{HDI}^{\mathrm{b}}$ & $0.800(62 \mathrm{nd})$ & 0.796 (66th) & .846 (44th) & $0.910(27 \mathrm{th})$ \\
\hline Unemployment rate $\mathrm{c}^{\mathrm{c}}$ & $31.1 \%$ & $53.3 \%$ & $18.0 \%$ & $2.7 \%$ \\
\hline War and conflicts indicators & - & + & - & + \\
\hline Dates & 1992-1995 & 2001 & 1991-1995 & 1991 \\
\hline Intensity level of conflicts ${ }^{\mathrm{d}}$ & War & Minor & War & Minor \\
\hline War victims rate ${ }^{c}$ & $64.4 \%$ & $12.7 \%$ & $23.8 \%$ & $0.7 \%$ \\
\hline
\end{tabular}

Note: BiH Bosnia and Herzegovina; FYROM Former Yugoslav Republic of Macedonia. Symbols specify where the situation is relatively better $(+)$ or worse $(-)$ according to the indicators

a GDP $=$ Evolution of gross domestic product per capita, from 2000 until 2004, World Bank Group, 2007

b $\mathrm{HDI}=$ Human Development Index, 2004 values (worldwide rank in parentheses), United Nations Development Program (2006)

c Rates in the sample

d According to the classification of the International Peace Research Institute, Oslo/Uppsala Conflict Data Program (Gleditsch, Wallensteen, Eriksson, Sollenberg, \& Strand, 2002; Harbom, 2007); war = at least 1,000 battle-related deaths in a given year, minor = between 25 and 999 battle-related deaths in a given year

conflicts were not only longer than those in the two other countries, but their intensity level was also higher. The other two countries underwent shorter conflicts with fewer casualties. Regarding the socioeconomic situation, Bosnia and Herzegovina and Macedonia exhibited the lowest levels of GDP as well as a smaller increase from 2000 to 2004 compared to the others. The Human Development Index (HDI; an indicator that combines life expectancy, educational attainment, and income) reflected the same pattern: Slovenia exhibited the highest score, followed by Croatia and weaker scores were observed for Bosnia and Herzegovina and the Republic of Macedonia. Slovenia can be considered as a control group, as it was relatively spared. On the contrary, Bosnia and Herzegovina cumulated a difficult socioeconomic situation with a recent past of strong victimization due to war and conflicts.

\section{Participants}

The sample consists of 598 young adults, 148 who reside in Bosnia and Herzegovina, 150 in Croatia, 150 in the Former Yugoslav Republic of Macedonia, and 150 in Slovenia. Men $(n=294)$ and women $(n=304)$ are equally represented in each context. Respondents are 30-36 years old, with an average age of 32.7 years. The average age of respondents is similar across countries, and between men and women. The ratios of respondents that are looking for a job or unemployed (versus those who are working) in each sample reveal a worse situation in Bosnia 
and Herzegovina and Macedonia compared to the other two countries, which is consistent with the macro-indicators of socioeconomic situation (see Table 1). Similarly, rates of war victims (for the computation of the indicator see measures section) are highest in Bosnia and Herzegovina, followed by Croatia, in accordance with macro-level indicators of war and conflicts.

\section{Procedure}

Standardized face-to-face interviews were conducted at respondents' homes in each of the four countries. The study was presented as a survey on experiences during entry into adult life in the respondent's country and other European countries under the leadership of the University of Lausanne in Switzerland. No financial incentives were given to respondents. Interviewers stressed that each person of the individual's generation should feel entitled to participate and that this was important for the validity of the study.

In each questionnaire, participants were asked to complete a life calendar that recorded (in months) the dates when various events occurred in their life (for the use of life calendars, see e.g., Axinn, Pearce, \& Ghimire, 1999; Freedman, Thornton, Camburn, Alwin, \& Young-DeMarco, 1988). The interview began with positive events linked with the transition to adulthood followed by negative events due to exclusion or war. A recent publication on these data showed that the dates when people considered themselves as war victims, depending on the country they were in at that time, corresponded to the dates of conflicts (Spini, Fasel, \& Elcheroth, 2007). In the sub-sample of Croatia, the majority of victimization due to war occurred in 1991, and it continued until 1995. The majority of war victims in Bosnia and Herzegovina were stricken between 1992 and 1995. In the Republic of Macedonia, all of the victims of war were recorded in 2001. The second part of the interview included political and attitudinal scales. The completion of the total questionnaire required approximately one hour.

The original English questionnaire was translated by native-speaking translators in the four languages of the survey: Bosnian, Croatian, Macedonian, and Slovenian. The procedure included back-translations in English by independent translators and systematic back-checks of these versions by the Lausanne coordination team. PRISM Research, a private institute based in Sarajevo, handled translations, fieldwork, and data entry. Only experienced local interviewers (65 individuals) were recruited and trained to conduct the fieldwork. Sampling occurred as follows. For every country, 15 municipalities were randomly selected. Five municipalities were chosen from those with the largest populations, five from those with medium-size populations and five from those with the smallest populations. In each municipality, 10 respondents were selected using a random walk procedure. Individuals were eligible for the study if they were born between 1968 and 1974 and resided in the country of interview on their 15th birthday. Respondents were, therefore, all 15 years old between 1983 and 1989 and started their transition to adulthood in a context and a period shaken by conflicts and instability. The data collection took place in December 2004. 


\section{Measures}

Belief in a just world was measured with the Dalbert, Montada, and Schmitt scale (1987). Subjects answered six items (for instance, "I think basically the world is a just place" or "I believe that, by and large, people get what they deserve") on a 7-point Likert scale that ranges from 1 (strongly disagree) to 7 (strongly agree). Internal score reliability (Cronbach's alpha) per country varies from 0.77 (Slovenia) to 0.81 (Macedonia) and equals 0.81 for the total sample.

The variables that represent victimization are dichotomous. Someone is considered a victim as soon as the first victimization episode takes place. Two categories of possible negative events were defined. The first category considers negative life experiences of exclusion, may they be social, economical, or political. The second category represents negative life experiences that happened as a consequence of war. For each event, subjects answered whether or not the event occurred after their 15th birthday. Then, the month and year that the event occurred were recorded in a life calendar. A person is considered as an exclusion victim is if she/he answered that at least one of the following events happened to her/him: "Has there been a period in your life during which the material resources of your household did not allow you to assure your basic needs? (food, clothes, education, health)?"; "Have you ever been homeless (living in the street or in a collective shelter)?"; "Has there been a period in your life during which you were cut off from people that are important in your life?"; "Has there been a period in your life during which you have been treated in an arbitrary way by the police or the justice system?"; "Has there been a period in your life during which you have been treated in a discriminatory way by an administration or company, because of belonging to a particular group? (because of your ethnicity, gender, or religion)"; "Has there been a period in your life during which you have been hindered to express your opinion in public?"; "Has there been a period in your life during which you have been threatened or intimidated because of supporting a political or religious association or movement?". The non-victims of exclusion, on the other hand, are the persons who answered negatively to each of these seven questions.

In a similar way, a war victim is a person who answered that at least one of the following events happened to her/him personally as a consequence of war, since the age of 15: "Have you been forced to leave your home and live elsewhere?"; "Have you ever been imprisoned, kidnapped or taken hostage?"; "Has a member of your immediate family been killed during the armed conflict (son, daughter, father, mother, brother, sister, grandmother, or grandfather)?"; "Has there been serious damage to your property (to your belongings)?"; "Have you been wounded by the fighting?"; "Did you have your house looted?" The non-victims of war are those who answered negatively to each of these six questions.

The number of exclusion events is the sum of different negative events among the seven above-mentioned events that a victim of exclusion might have endured from when he/she was 15 years of age until the time of the interview. This measure ranges from 1 to 7 . Similarly, the number of war events is the total number of war victimization events experienced by a war victim among the six possibilities presented above. This measure ranges from 1 to 6 . 
Temporal distance is the number of years between the first victimization event (the first time this person became a victim) and the time of the interview. The time interval taken into account begins with the individual's 15 th birthday. The more recent this first event, the weaker the indicator. Two indicators are computed, one for the temporal distance since the first exclusion event, another for the time since the first war event.

\section{Results}

\section{Victimization}

Table 2 displays the means of the victimization variables. As these are dummy variables, means correspond to rates of victims. The highest proportion of war victims was observed among respondents in Bosnia and Herzegovina. Nearly twothirds of these respondents were war victims, compared to less than one-fourth in Croatia, one-eighth in Macedonia and only one person in Slovenia. Similar patterns were found for victims of exclusion, although at a higher level. Individuals living in Bosnia and Herzegovina experienced the most victimization, with three-fourths of the sample stating that they experienced at least one exclusion event. The rate was also high in Croatia and Macedonia, with more than half and more than one-third of the sample affected, respectively. Individuals in Slovenia were less affected, although one-quarter reported having been victims of exclusion. The percentage of people who were victims in each context, of war and/or exclusion, was $88.7 \%$ for Bosnia and Herzegovina, 58.2\% for Croatia, $45.0 \%$ for the Republic of Macedonia, and $24.8 \%$ for Slovenia.

The positive correlations between war and exclusion victims in Bosnia and Herzegovina and Croatia (Table 2) are due to the fact that $87 \%$ of war victims were also victims of exclusion. On the other hand, $42 \%$ of exclusion victims were not victims of war. There is no such correlation in the two other samples.

\section{Context, Victimization and Belief in a Just World ${ }^{1}$}

The first analysis focused on possible variations in endorsing the belief in a just world depending on the context in which the individual resided (Hypothesis 1), and in light of victimization experiences that he/she experienced (Hypothesis 2). We conducted a hierarchical multiple regression analysis on the total sample with the belief in a just world as the dependent variable. The analysis was done stepwise, with each new step embedded into the next step. At the first step, individuals' country of residence was entered as a dummy variable. Slovenia was the reference group because of its relatively better situation. Indicators for the other three countries were thus interpreted in comparison with Slovenia. Victimization

\footnotetext{
${ }^{1}$ For all of the following analyses, the effects of age and gender were tested. Given that there was no statistically significant effect of age on the belief in a just world and only a marginal effect of sex in Croatia (women believed more than men), which did not alter the remaining results, these variables were not included in the reported analyses.
} 
Table 2 Means, standard deviations, and correlations of belief in a just world (BJW) with victimization variables across countries

\begin{tabular}{|c|c|c|c|c|c|}
\hline & $M$ & $S D$ & 1 & 2 & 3 \\
\hline \multicolumn{6}{|l|}{$\mathrm{BiH}(n=140)$} \\
\hline 1. BJW & 3.63 & 1.44 & - & $-0.15^{\dagger}$ & $-0.22 *$ \\
\hline 2. Exclusion victim & 0.81 & 0.40 & & - & $0.27 * *$ \\
\hline 3. War victim & 0.66 & 0.47 & & & - \\
\hline \multicolumn{6}{|l|}{ Croatia $(n=141)$} \\
\hline 1. BJW & 4.28 & 1.19 & - & 0.05 & 0.04 \\
\hline 2. Exclusion victim & 0.54 & 0.50 & & - & $0.32 * *$ \\
\hline 3. War victim & 0.24 & 0.43 & & & - \\
\hline \multicolumn{6}{|l|}{ FYROM $(n=148)$} \\
\hline 1. BJW & 3.08 & 1.37 & - & $-0.19 *$ & 0.01 \\
\hline 2. Exclusion victim & 0.38 & 0.49 & & - & 0.03 \\
\hline 3. War victim & 0.13 & 0.34 & & & - \\
\hline \multicolumn{6}{|l|}{ Slovenia $(n=149)$} \\
\hline 1. BJW & 3.96 & 1.05 & - & 0.04 & -0.01 \\
\hline 2. Exclusion victim & 0.25 & 0.43 & & - & 0.14 \\
\hline 3. War victim & 0.01 & 0.08 & & & - \\
\hline
\end{tabular}

Note: BiH Bosnia and Herzegovina; FYROM Former Yugoslav Republic of Macedonia. Victimization variables are coded as $0=$ non victim, $1=$ victim

${ }^{\dagger} p<.10 ; * p<.05 ; * * p<.01$

variables were entered at further steps: victim of exclusion at Step 2 and war victim at Step 3. All possible interaction effects between victimization variables and each country were tested, and only those interactions that were statistically significant at one step were reported and entered into the next step.

As shown in Table 3, at Step 1, the mean level of adherence to the belief in a just world differed significantly in each country compared to Slovenia. The adherence in Croatia was higher; it was lower in Bosnia and Herzegovina, and lowest in Macedonia. At Step 2, the victim of exclusion variable was introduced and interaction effects with countries that were found to be significant were reported. By including these variables, the model improved $(\Delta F=3.51, p<.05)$. Two interaction terms were significant. When countries levels were taken into account, victimization due to exclusion was significant only in Bosnia and Herzegovina and Macedonia. Victims of exclusion were less likely to endorse the idea that the world is a just place only in the countries where the socioeconomic situation was the worst. At the third step, the variable war victim was added, as well as the only significant interaction effect, which significantly improved the model $(\Delta F=3.09$, $p<.05$ ). The results showed that being a war victim diminished the belief in a just world's endorsement only in Bosnia and Herzegovina, where the rates of victims of war were the highest compared to the other three countries. Furthermore, in this context, the effect of being a war victim was more important for the decline of belief in a just world than being a victim of exclusion, as the interaction term between 


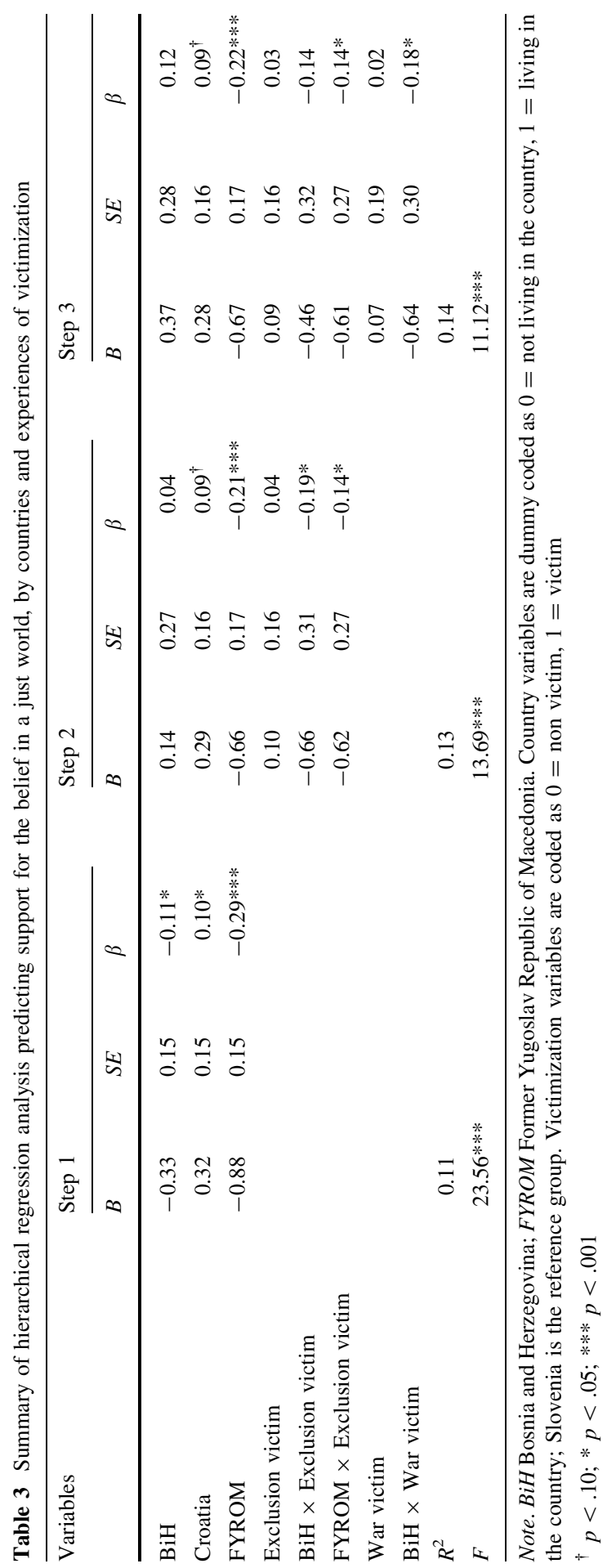


Bosnia and Herzegovina and exclusion victim became non-significant at the third step. Once the victimization variables and interactions were taken into account, differences between Slovenia and Croatia and between Slovenia and Bosnia and Herzegovina were non-significant. The fact that war victims were less likely to believe in a just world in Bosnia and Herzegovina explained the average difference with Slovenia. However, in the Republic of Macedonia, the variable exclusion victim partially explained the lower level of adherence to the belief in a just world compared to Slovenia.

We partially verified our first hypothesis (social anchoring). The level of belief in a just world in Slovenia and Croatia was higher than that in Bosnia and Herzegovina and the Republic of Macedonia. Yet, the level in Macedonia was even lower and the variables considered were not sufficient to explain this effect. The second hypothesis (personal experiences) was validated, but only in contexts with a less favorable socioeconomic situation; personally victimized individuals adhered less to the idea of living in a just world than non-victims. This observation concerned war victims in Bosnia and Herzegovina (two-thirds of the country's sample) and the victims of exclusion in the Republic of Macedonia (one-third of the country's sample) and in Bosnia and Herzegovina (four-fifths of the sample).

\section{Accumulation of Negative Events and Temporal Effects}

Next, we examined whether there was a negative accumulation effect operationalized as a weaker level of belief in a just world when victimization episodes were more numerous (Hypothesis 3). Second, following the idea that the belief system of traumatized persons can be restored with time, we investigated whether individuals' endorsement of belief in a just world was greater if the negative episode was farther in time (Hypothesis 4). The analyses focused on the sub-sample of victims whose support of the belief in a just world was previously shown to be lower than that of their non-victims counterparts (i.e., victims of exclusion in Bosnia and Herzegovina $(n=100)$ and in the Republic of Macedonia $(n=55)$ as well as war victims in Bosnia and Herzegovina $(n=82))$.

The number of exclusion events experienced by the sub-sample of victims was significantly higher in Bosnia and Herzegovina than in Macedonia, $F$ (1, $153)=18.73, p<.001$ (see Table 4). The temporal distance since the first exclusion event ranged from 1.25 to 20.25 years prior to the interview. This distance was widely distributed across time in Macedonia, whereas it was more stricken in Bosnia and Herzegovina, where three-quarters of the first exclusion events occurred during the war period between 1992 and 1995. Temporal distance since the first war victimization in Bosnia and Herzegovina varied from 4.75 to 16.75 years; however, $90 \%$ occurred during the war period.

Similar to the first analyses, hierarchical multiple regressions on the sub-sample of exclusion victims of Bosnia and Herzegovina and Macedonia were run, with the belief in a just world as the dependent variable. At the first step, individuals' country of residence was controlled for by entering Bosnia and Herzegovina as a dummy variable. Macedonia was the reference group. Unsurprisingly, the mean score on the belief in a just world scale for victims of exclusion was higher in Bosnia and 
Table 4 Means, standard deviations, and correlations of belief in a just world (BJW) with accumulation and temporal indicators for victim sub-samples in BiH and FYROM

\begin{tabular}{lrrccc}
\hline \multicolumn{1}{l}{$M$} & $S D$ & 1 & 2 & 3 \\
\hline $\begin{array}{l}\text { Exclusion victims } \\
\text { BiH }(n=100)\end{array}$ & & & & & \\
1. BJW & 3.54 & 1.52 & - & -0.11 & 0.15 \\
2. Number of events & 2.35 & 1.43 & & - & $0.18^{\dagger}$ \\
3. Temporal distance & 11.45 & 2.95 & & & - \\
FYROM $(n=55)$ & & & & $-0.29^{*}$ & $0.28^{*}$ \\
1. BJW & 2.79 & 1.28 & - & - & -0.01 \\
2. Number of events & 1.45 & 0.74 & & & - \\
3. Temporal distance & 10.76 & 5.65 & & & 0.09 \\
War victims & & & & - & - \\
BiH ( $n=82)$ & & & & & \\
1. BJW & 3.57 & 1.41 & - & & 0.15 \\
2. Number of events & 2.04 & 1.01 & & & \\
3. Temporal distance & 10.82 & 1.71 & & & \\
\hline
\end{tabular}

Note: BiH Bosnia and Herzegovina; FYROM Former Yugoslav Republic of Macedonia. Number of events is number of exclusion events for exclusion victims and number of war events for war victims. Temporal distance is the number of years past from the first exclusion or the first war victimization event until December 2004 (date of interview)

${ }^{\dagger} p<.10 ; * p<.05$

Table 5 Hierarchical regression analysis predicting support for the belief in a just world for exclusion victims in $\mathrm{BiH}$ and Macedonia

\begin{tabular}{|c|c|c|c|c|c|c|}
\hline \multirow[t]{2}{*}{ Variables } & \multicolumn{3}{|l|}{ Step 1} & \multicolumn{3}{|l|}{ Step 2} \\
\hline & $B$ & $S D$ & $\beta$ & $B$ & $S D$ & $\beta$ \\
\hline $\mathrm{BiH}$ & 0.75 & 0.24 & $0.24 * *$ & 0.87 & 0.25 & $0.28 * * *$ \\
\hline Number of exclusion events & & & & -0.19 & 0.09 & $-0.17 *$ \\
\hline Temporal distance (years) & & & & 0.07 & 0.03 & $0.21 * *$ \\
\hline$R^{2}$ & 0.06 & & & 0.12 & & \\
\hline$F$ & $9.63^{* *}$ & & & $6.90 * *$ & & \\
\hline
\end{tabular}

Note: $\mathrm{BiH}$ Bosnia and Herzegovina. $\mathrm{BiH}$ is a dummy variable coded as $0=$ not living in $\mathrm{BiH}, 1=$ living in $\mathrm{BiH}$. Macedonia is the reference group

$* p<.05 ; * * p<.01 ; * * * p<.001$

Herzegovina than in Macedonia (see Table 5). At step 2, the number of negative events experienced by the person was introduced together with the temporal distance to the first negative experience. The addition of these variables improved the model $(\Delta F=5.27 ; p<.01)$. The more often a person experienced negative events, the lower his/her belief in a just world. At the same time, the more remote the first event was in time, the stronger was one's support for the belief in a just world. In other words, the more recent the event was, the weaker was one's support 
for the belief. In more concrete terms, in Bosnia and Herzegovina and Macedonia, victims of exclusion were less likely to believe in a just world than were nonvictims. When controlling for country levels, for each additional year after the first victimization event, the belief in a just world scored 0.07 higher. Meanwhile, for each new exclusion event, the belief scored 0.19 lower.

In the sub-sample of war victims in Bosnia and Herzegovina, the correlation matrix (Table 4) indicates no significant link between the number of war events and the belief in a just world. Because the dates for the first war victimization in Bosnia and Herzegovina were similar across individuals, the temporal distance at the first victimization event due to war was not tested.

To summarize these results, we did not find a negative cumulative effect of war experiences on the belief in a just world for war victims in Bosnia and Herzegovina. However, we observed a cumulative negative effect for victims of exclusion in Bosnia and Herzegovina and the Republic of Macedonia when we control for the temporal distance to the first victimization. Moreover, in this last situation, the more remote was this first negative event, the stronger was one's belief. Thus, the third (cumulative effect) and fourth hypotheses (time) were validated for victims of exclusion in Bosnia and Herzegovina and the Republic of Macedonia, but not for war victims.

\section{Discussion}

We compared the belief in a just world among young adults living in four countries in the former Yugoslavia: Bosnia and Herzegovina, Croatia, Republic of Macedonia, and Slovenia. Contrary to conceptualizing the belief in a just world as a stable concept through time and situations (Dalbert, 2001), we have made the assumption that, in situations of strong victimization, the general belief in a just world-in the manner of fundamental or basic beliefs (Janoff-Bulman, 1992; Epstein, 1973) — is shaken and thus decreases. Victimization was considered on two levels: the contextual level, by considering the negative consequences of recent conflicts and current socioeconomic status, and the individual level, with interest for victimization episodes a person faced.

The results showed, on the one hand, contextual differences in the belief in a just world, and, on the other hand, a negative effect of victimization experiences. However, this effect depends on the context in which the individual has been living. In Bosnia and Herzegovina and Macedonia, victims of exclusion are less likely to believe in a just world than non-victims, but this difference is not found for victims of Croatia or Slovenia. This diminution effect is only found in the two contexts in which the socioeconomic situation was the most unfavorable at the time of data collection. The war victims adhere less strongly to the idea that the world is just than non-victims, but this effect is only observed in the context of Bosnia and Herzegovina, in which nearly two-thirds of the sample was hit by a war trauma (whereas this is the case for less than one-quarter of the Croatian sample, one-eighth in the Republic of Macedonia and practically no one in Slovenia). Being a victim of war supplants the effect of being a victim of exclusion in Bosnia and Herzegovina. 
These victimization variables, at an individual level, partially explain why the level of belief in a just world is lower in the Republic of Macedonia than in Croatia, and Slovenia. These variables entirely explain why the level of belief is lower in Bosnia and Herzegovina. Other variables must therefore be invoked to explain why the respondents of the Macedonia sub-sample are less likely to subscribe to the idea that the world is just than those in other contexts. The explanation for this difference may be found at a societal level by the deleterious socioeconomic situation or by the short time that had passed since the conflicts (in 2001). These results allow us to consider that the belief in a just world's endorsement may vary across situations.

We found a negative effect of cumulative negative events, in line with the results reported by Cubela Adoric (2004) and Catlin and Epstein (1992). Indeed, for the victims of exclusion in Bosnia and Herzegovina and in Macedonia, the more negative events that individuals were personally confronted with, the lower the level of their belief in a just world. However, this negative accumulation was not observed for victimization due to war in Bosnia and Herzegovina. A positive effect linked to time was underlined for victims of exclusion in Bosnia and Herzegovina and Macedonia. Victims whose first negative event was far away in time showed stronger support for the belief in a just world than those for which the event was more recent. These results are in line with Janoff-Bulman's model (1992): The belief a person has 'that the world is just' is shaken when this person is victimized because reality contradicts this belief. Thus, the victim integrates this traumatic event into his/her assumptive world. The belief that the world is a just place will be restored over time, or will decline if one experiences additional negative events.

The impact of victimization on the belief in a just world is also dependent on the context in which the individual is inserted. When victimization is experienced on an individual basis, it may be possible to adopt coping strategies to preserve the belief in a just world. By contrast, when experiences are widely shared in a societal context, the belief in a just world may be shattered at a societal level (Ferguson, 2000).

In fact, our results indicate that it is difficult to continue believing in a just world if society as a whole appears unjust. At first sight, this conclusion may be at odds with the meta-analysis of Malahy et al. (2009), who showed that increases in injustice due to income disparities were correlated with higher levels of belief in a just world. However, essential differences exist between the studies taken into consideration in this meta-analysis and the current study. The meta-analysis included US undergraduate students, a rather different sample from the random sample of young adults aged between 30 and 36 years old used here. Moreover, the contexts are fundamentally different. First, the socioeconomic level of the USA, with an HDI of 948 in 2004 (8th rank worldwide), is much higher than those of countries such as Bosnia and Herzegovina or Macedonia. Another main difference is that the current study did not deal with observers of victimizations, but with actual victims. The events that they were subjected to at the collective level and those that they personally experienced were due to fratricidal conflicts or severe economic precariousness. These high levels of collective vulnerability create a qualitatively different context than that which can be observed in studies run in the USA or comparable countries with victims or observers of victims. The challenge of maintaining core beliefs likely varies in such different contexts. There may be a 
threshold at which the strategies to maintain or restore the belief in a just world are no longer effective due to obvious massive injustice and collective vulnerability. Our study suggests that a necessary condition for undermining the belief in a just world is that individuals share a common fate (Rabbie, 1998).

Subsequently, belief restoration in the aftermath of war would not only depend on individual coping processes but also on collective processes taking place in specific social contexts. Indeed, if the belief in a just world is built in the early years of life by confrontation with the environment (Lerner, 1977), reconstruction of this belief is likely to occur similarly. When the daily landscape presents a context in which everyone can rebuild a "normal" life, believing in a just world is again possible, which is not the case in a context that fails to heal its wounds. It is thus conceivable that adherence to the belief in a just world in Croatia was lower after the bloody events of the early 1990s. However, in this context, in which the GDP and the HDI are now superior to those of Bosnia and Herzegovina or Macedonia, the process of restoring the beliefs in a just world may have occurred faster. Of course, only longitudinal data would allow verifying this hypothesis; we cannot rule out that Croatian residents' levels of belief in a just world remained stable despite the traumatic experiences that this country endured. What is impressive is that we observe a direct relationship between past war victimization and low levels of belief in a just world in Bosnia and Herzegovina even nine years after the war.

Taken altogether, these results indicate that belief in a just world may vary over time and across situations. It would be interesting to extend the scope of this investigation to other countries that have endured high levels of victimization and to establish more precise contextual indicators for the background where people live. It would also be necessary to take into account other variables at the individual level, such as socioeconomic status indicators and group affiliations (ethnic, religious).

\section{Conclusion}

In conclusion, we tested the limits of stability and the resistance of the fundamental belief in a just world (Lerner, 1965). Numerous experiences of victimization, such as political or socioeconomic exclusion or war trauma, when widely shared in a societal context, can threaten the belief in a just world by making it decrease at societal and individual levels. This may occur because reality comes into opposition with this belief and it becomes unsustainable to continue defending the idea that the world is just. In addition, the accumulation of negative experiences leads to an additional decline in the belief in a just world. The belief, however, may be restored over time. This process, including the time required, depends not only on individual coping mechanisms, but also on the context in which the individual faces and experiences the event, and as a consequence depends on agents of societal order that participate in its reconstruction. Defined as a fundamental delusion, Lerner (1980) argues that believing in a just world is essential for people's sense of sanity. Thus, it is necessary after a war-torn period to offer people a chance to reconstruct the landscape where they live, in order to restore the healthy feeling that the world is a place of justice. 
Acknowledgments We would like to thank Willem Doise and Guy Elcheroth for their thoughtful comments on a previous version of this manuscript. This study was supported by the Swiss National Science Foundation, Grant No 101412-103664/1, and 100012-109623/1, and by the PaVie Center for Life Course and Life Style Studies, University of Lausanne.

\section{References}

Axinn, W. G., Pearce, L. D., \& Ghimire, D. (1999). Innovations in life history calendar applications. Social Science Research, 28, 243-264.

Catlin, G., \& Epstein, S. (1992). Unforgettable experiences: The relation of life events to basic beliefs about self and world. Social Cognition, 10(2), 189-209.

Cubela Adoric, V. (2004). Belief in a just world and young adults' ways of coping with unemployment and the job search. In C. Dalbert \& H. Sallay (Eds.), The justice motive in adolescence and young adulthood (pp. 189-214). London: Routledge.

Cubela Adoric, V., \& Kvartuc, T. (2007). Effects of mobbing on justice beliefs and adjustment. European Psychologist, 12(4), 261-271.

Dalbert, C. (1999). The world is more just for me than generally: About the personal belief in a just world scale's validity. Social Justice Research, 12(2), 79-98.

Dalbert, C. (2001). The justice motive as a personal resource: Dealing with challenges and critical life events. New York: Kluwer Academic/Plenum.

Dalbert, C., Montada, L., \& Schmitt, M. (1987). Glaube an eine gerechte Welt als Motiv: Validierungskorrelate zweier Skalen [Belief in a just world: Validation correlates of two scales]. Psychologische Beitrage, 29, 596-615.

Dalbert, C., \& Schneider, A. (1995). Die Allgemeine Gerechte-Welt-Skala: Dimensionalität, Stabilität und Fremdurteiler-Validität (Berichte aus der Arbeitsgruppe "Verantwortung, Gerechtigkeit, Moral" Nr. 86). Universität Trier, FBI-Psychologie.

Dalbert, C., \& Stoeber, J. (2006). The personal belief in a just world and domain-specific beliefs about justice at school and in the family: A longitudinal study with adolescents. International Journal of Behavioral Development, 30(3), 200-207.

Dzuka, J., \& Dalbert, C. (2007). Student violence against teachers: Teachers' well-being and the belief in a just world. European Psychologist, 12(4), 253-260.

Epstein, S. (1973). The self-concept revisited, or a theory of a theory. American Psychologist, 28, 404-416.

Ferguson, N. (2000). The impact of sectarian justice and the paramilitary ceasefires on adolescent just world beliefs in Northern Ireland. Irish Journal of Psychology, 21(1-2), 70-77.

Fletcher, K. (1988). Belief systems, exposure to stress, and post-traumatic stress disorder in Vietnam veterans. Doctoral Dissertation, University of Massachusetts at Amherst.

Freedman, D., Thornton, A., Camburn, D., Alwin, D., \& Young-DeMarco, L. (1988). The life history calendar : A technique for collecting retrospective data. Sociological Methodology, 18, 37-68.

Furnham, A. (1993). Just world beliefs in twelve societies. Journal of Social Psychology, 133(3), $317-329$.

Furnham, A. (2003). Belief in a just world: Research progress over the past decade. Personality and Individual Differences, 34, 795-817.

Furnham, A., \& Procter, E. (1989). Belief in a just world: Review and critique of the individual difference literature. British Journal of Social Psychology, 28, 365-384.

Garde, P. (2000). Vie et mort de la Yougoslavie [Life and death of Yugoslavia]. Paris: Fayard.

Gleditsch, N. P., Wallensteen, P., Eriksson, M., Sollenberg, M., \& Strand, H. (2002). Armed conflict 1946-2001: A new dataset. Journal of Peace Research, 39(5), 615-637.

Glennon, F., Joseph, S., \& Hunter, J. (1993). Just world beliefs in unjust societies: Northern Ireland. The Journal of Social Psychology, 133, 591-592.

Gluhoski, V. L., \& Wortman, C. B. (1996). The impact of trauma on world views. Journal of Social and Clinical Psychology, 15(4), 417-429.

Hafer, C. L., \& Bègue, L. (2005). Experimental research on just-world theory: Problems, developments, and future challenges. Psychological Bulletin, 131(1), 128-167. 
Harbom, L. (2007). PRIO (International Peace Research Institute, Oslo)/UCDP (Uppsala Conflict Data Program) Armed Conflict Dataset Codebook, Version 4-2007. Retrieved July 28, 2008, from http://www.prio.no/CSCW/Datasets/Armed-Conflict/UCDP-PRIO/4-2007

Hunt, M. (2000). Status, religion, and the "belief in a just world": comparing African Americans, Latinos, and Whites. Social Science Quarterly, 81, 325-343.

Janoff-Bulman, R. (1992). Shattered assumptions. Towards a new psychology of trauma. New York: The Free Press.

Kay, A. C., \& Jost, J. T. (2003). Complementary justice: Effects of "poor but happy" and "poor but honest" stereotype exemplars on system justification and implicit activation of the justice motive. Journal of Personality and Social Psychology, 85, 823-837.

Lerner, M. J. (1965). Evaluation of performance as a function of performer's reward and attractiveness. Journal of Personality and Social Psychology, 1, 355-360.

Lerner, M. J. (1977). The justice motive: Some hypotheses as to its origins and forms. Journal of Personality, 45, 1-52.

Lerner, M. J. (1980). The belief in a just world: A fundamental delusion. New York: Plenum Press.

Lerner, M., \& Miller, D. (1978). Just world research and the attribution process: Looking back and ahead. Psychological Bulletin, 85, 1030-1051.

Lerner, M. J., \& Simmons, C. H. (1966). Observer's reaction to the "innocent victim": Compassion or rejection? Journal of Personality and Social Psychology, 4, 203-210.

Lipkus, I. M., Dalbert, C., \& Siegler, I. C. (1996). The importance of distinguishing the belief in a just world for self versus for others: Implications for psychological well-being. Personality and Social Psychology Bulletin, 22, 666-677.

Malahy, L. W., Rubinlicht, M. A., \& Kaiser, C. R. (2009). Justifying inequality: A cross-temporal investigation of U.S. income disparities, just-world beliefs from 1973 to 2006. Social Justice Research, 22, 369-383.

Otto, K., Boos, A., Dalbert, C., Schöps, D., \& Hoyer, J. (2006). Posttraumatic symptoms, depression, and anxiety of flood victims: The impact of the belief in a just world. Personality and Individual Differences, 40, 1075-1084.

Otto, K., \& Dalbert, C. (2005). Belief in a just world and its functions for young prisoners. Journal of Research in Personality, 39, 559-573.

Rabbie, J. M. (1998). Is there a discontinuity or a reciprocity effect in cooperation and competition between individuals and groups? European Journal of Social Psychology, 28, 483-507.

Schneider, A., Meissner, A., Montada, L., \& Reichle, B. (1987). Validierung von Selbstberichten über Fremdratings (=Berichte aus der Arbeitsgruppe "Verant-wortung, Gerechtigkeit, Moral" Nr. 41). Trier: Universität Trier.

Spini, D., Fasel, R., \& Elcheroth, G. (2007). Collective vulnerability, morality, and intergroup conflict: The beast, the angel and the madman. In V. C. Adoric (Ed.), 15th Psychology days in Zadar: Book of selected proceedings (pp. 53-67). Zadar: University of Zadar.

United Nations Development Programme. (2006). Human development report 2006: Beyond scarcity: Power, poverty and the global water crisis. Retrieved July 28, 2008, from http://hdr.undp.org/ en/media/hdr06-complete.pdf

Wilmer, F. (2002). The social construction of man, the state and war: Identity, conflict, and violence in former Yugoslavia. New York: Routledge.

World Bank Group. (2007). World development indicators [GDP (current US\$)]; [Population, total]. Retrieved July 28, 2008, from http://www.worldbank.org 